\title{
Effect of clinical condition and mycophenolate mofetil on plasma retinol, $\alpha$-tocopherol and $\beta$-carotene in renal transplant recipients
}

Jolanta Kamińska², Joanna Sobiak, Maciej Głyda², Grażyna Duda³, Małgorzata Nogala-Kałucka4, Aleksander Siger ${ }^{4}$, Maria Chrzanowska ${ }^{1}$

1Department of Physical Pharmacy and Pharmacokinetics, Poznan University of Medical Sciences, Poland

2Department of Transplantology and General Surgery, District Hospital, Poznan, Poland ${ }^{3}$ Department of Bromatology, Poznan University of Medical Sciences, Poland

${ }^{4}$ Department of Biochemistry and Food Analysis, Poznan University of Life Sciences, Poland

Submitted: 20 April 2011

Accepted: 14 January 2012

Arch Med Sci 2012; 8, 2: 256-262

DOI: 10.5114 /aoms.2012.28553

Copyright ( 2012 Termedia \& Banach

\section{Abstract}

Introduction: Plasma antioxidant vitamins (retinol, $\alpha$-tocopherol, $\beta$-carotene) were measured to establish the influence of clinical condition and mycophenolate mofetil (MMF) treatment on the nutritional status of renal transplant recipients.

Material and methods: In 106 adult patients plasma vitamins were measured and 24-h diet history questionnaires were conducted. The MMF influence on plasma vitamins was verified in 61 patients.

Results: The current dietary intakes of vitamins in daily food rations were lower than recommended. Plasma retinol was lower in patients suffering from gastrointestinal disorders $(1.25 \pm 0.48 \mathrm{mg} / \mathrm{l}$ vs. $1.55 \pm 0.70 \mathrm{mg} / \mathrm{l})$ and inversely associated with aminotransferases activity $(p=0.019)$ and creatinine clearance $(p=0.021)$. Retinol concentrations were positively associated with plasma creatinine $(p=0.027)$ and pharmacokinetic parameters of MMF phenyl glucuronide. $\beta$-Carotene concentrations were higher in women $(0.39 \pm 0.46 \mathrm{mg} / \mathrm{l}$ vs. 0.28 $\pm 0.23 \mathrm{mg} / \mathrm{l} ; p=0.041)$ and when MMF was co-administered with cyclosporine vs. tacrolimus ( $0.45 \pm 0.62 \mathrm{mg} / \mathrm{l}$ vs. $0.25 \pm 0.19 \mathrm{mg} / \mathrm{l})$. Plasma $\alpha$-tocopherol correlated negatively with the mycophenolic acid pre-dose concentration $(p=0.027)$ and was significantly lower in patients treated with calcineurin inhibitors (8.90 $\pm 5.23 \mathrm{mg} / \mathrm{l}$ vs. $12.25 \pm 5.62 \mathrm{mg} / \mathrm{l}$ ). A positive correlation was observed between $\alpha$-tocopherol levels and aspartate aminotransferase $(p=0.006)$. In multivariate regression aspartate aminotransferase and MMF treatment significantly influenced retinol $(p<0.001)$.

Conclusions: The MMF treatment was associated with significantly lower retinol concentrations. The gastrointestinal disorders occurrence in MMF-treated patients may cause a decrease in retinol absorption. Diet adjustment and/or vitamin A supplementation should be considered.

Key words: antioxidant vitamins, clinical condition, mycophenolate mofetil, renal transplantation, nutritional status.

\section{Introduction}

Malnutrition in renal transplant recipients intensifies coexisting diseases, deteriorates prognosis, increases mortality and morbidity as well

\author{
Corresponding author: \\ Assoc. Prof. \\ Maria Chrzanowska PhD \\ Department \\ of Physical Pharmacy \\ and Pharmacokinetics \\ Poznan University \\ of Medical Sciences \\ 6 Swiecickiego \\ 60-781 Poznan, Poland \\ Phone: +48 618546436 \\ Fax: +48 618546430 \\ E-mail: mchrzan@ump.edu.pl
}


as the cost of health care and, generally, it deteriorates the life quality of patients [1]. Malnutrition may result from gastrointestinal disorders, often leading to digestion and absorption disorders, as well as from concomitant diseases such as posttransplant diabetes, chronic liver disease and infections, which often occur in transplant recipients due to the various administered medications [2-6]. The majority of complications may be prevented or treated by early nutritional intervention and followup. Therefore, evaluation of the nutritional status as well as the analysis of risk factors concerning malnutrition have become more prevalent among physicians [1].

One of the factors influencing nutritional status in patients after solid organ transplantation may be the immunosuppressive agent administered. At present, mycophenolate mofetil (MMF) is the most widely used antiproliferative drug after solid organ transplantation [7]. The MMF was also found to be beneficial in children with idiopathic nephritic syndrome, primary glomerulonephritis and auto-antibody associated glomerulonephritis. Some authors recommend MMF to be a part of the standard treatment regimen for lupus nephropathy [8]. The MMF is often co-administered with calcineurin inhibitors (CNI) and corticosteroids [7, 9]. After oral administration, pharmacologically inactive MMF is rapidly and entirely hydrolyzed into an active metabolite, mycophenolic acid (MPA) $[2,10]$, which is further converted into an inactive phenyl glucuronide (MPAG) [11]. Although the appropriate diet may be contributory in reducing metabolic disorders [12], which often occur during immunosuppressive therapy, there have been, to our knowledge, few studies concerning MMF treatment and the nutritional status of renal transplant recipients.

Some of the disorders noted have been associated with oxidative stress. Therefore, an appropriate intake of antioxidant vitamins (tocopherols, retinol and carotenoids) may help prevent diabetes mellitus, cardiovascular and central neurodegenerative diseases as well as cancer [13-17]. However, in clinical practice, vitamin concentrations are rarely determined in patients during the post-transplant period, and there are few studies focusing on MMF [18].

The aim of the study was therefore to assess the influence of clinical condition, MMF treatment and the pharmacokinetics of its metabolites (MPA and MPAG) on vitamin nutritional status (retinol, $\alpha$-tocopherol and $\beta$-carotene) in renal transplant recipients.

\section{Material and methods}

\section{Patients}

The study included 106 renal transplant recipients aged 20-72 years in the late post-transplant period. In all patients sex and clinical condition such as diabetes, gastrointestinal disorders, liver function (alanine aminotransferase [ALT] and aspartate aminotransferase activity [AST] above or below $36 \mathrm{U} / \mathrm{l}$ ) as well as kidney function (plasma creatinine $\left[\mathrm{C}_{\mathrm{cr}}\right]$ above or below $1.5 \mathrm{mg} / \mathrm{dl}$; creatinine clearance $\left[\mathrm{CL}_{\mathrm{Cr}}\right]$ above or below $60 \mathrm{ml} / \mathrm{min}$ ) in relation to plasma vitamin concentrations were examined.

The MMF influence on plasma vitamins was studied in 61 renal transplant recipients aged 23-69 years treated with MMF (MMF group) with cyclosporine (CSA) $(n=28)$, tacrolimus (Tac) $(n=24)$ or without $\mathrm{CNI}(n=9)$. Almost all patients in this group were treated with corticosteroids ( $n=54)$. Additionally, the results were compared with a group of 45 renal transplant recipients aged $20-72$ years, treated with different immunosuppressive regimens excluding MMF and mycophenolate sodium (non-MMF group). Immunosuppressive regimens included corticosteroids $(n=42)$ in combination with CNI $(n=36)$, azathioprine $(n=16)$ or sirolimus $(n=12)$. Clinical characteristics of the patients are listed in Table I.

For vitamin analysis, blood samples from patients were collected into EDTA tubes after an overnight fast. The samples were centrifuged to obtain plasma and stored at $-20^{\circ} \mathrm{C}$ until analyzed.

The vitamin concentrations were analyzed in order to establish whether MMF treatment or MPA and MPAG pharmacokinetics could have influenced vitamin concentrations.

The study was approved by the Bioethical Committee at Poznan University of Medical Sciences and is in accordance with the Helsinki Declaration of 1975. Informed consent was obtained from the patients prior to initiating the study.

\section{Determination of vitamins}

The determination of plasma $\alpha$-tocopherol, retinol and $\beta$-carotene was based on standard methods [19-21] with some modifications. The reverse-phase HPLC method (Hewlett-Packard 1100) with a Supelcosil LC-18-DB column was applied for retinol and $\alpha$-tocopherol analyses. The normalphase HPLC method (WATERS 600) with a LiChrosorb Si 60 column was used for $\beta$-carotene analysis. The vitamin concentrations of standard solutions were prepared according to their absorbance values $(1 \mathrm{~cm} / 1 \%$ ) (for retinol 1835 at $325 \mathrm{~nm}$, for $\alpha$-tocopherol 75.8 at $290 \mathrm{~nm}$, for $\beta$-carotene 2590 at $450 \mathrm{~nm}$ ).

Into $200 \mu$ l of plasma, $20 \mu$ l of internal standard (IS) (retinol acetate $25 \mathrm{mg} / \mathrm{l}$ in ethanol) was added. For $\beta$-carotene determination, $20 \mu$ of hexane was added instead of IS. Subsequently, $500 \mu$ l of water, $500 \mu \mathrm{l}$ of ethanol with $0.04 \%$ of $\mathrm{BHT}$ (2,6-di-tertbutyl-4-methylphenol) and $1000 \mu \mathrm{l}$ of hexane with $0.04 \%$ BHT were added. The resulting solutions were shaken for $5 \mathrm{~min}$, vortex-mixed $(10 \mathrm{~min}$ at $1000 \times \mathrm{g})$ and $700 \mu \mathrm{l}$ of the organic layer was col- 
Table I. Characteristics of patients included in the study (mean \pm SD)

\begin{tabular}{|lccc|}
\hline Parameter & MMF group $(n=61)$ & Non-MMF group $(n=45)$ & All patients $(n=106)$ \\
\hline Age [years] & $43 \pm 12^{*}$ & $49 \pm 13^{*}$ & $46 \pm 13$ \\
\hline Post-transplant period [years] & $4.7 \pm 2.9^{*}$ & $6.6 \pm 3.1^{*}$ & $5.5 \pm 3.1$ \\
\hline Body weight [kg] & $74.9 \pm 16.7$ & $70.0 \pm 13.6$ & $72.9 \pm 15.6$ \\
\hline BMI [kg/m²] & $25.9 \pm 4.7$ & $24.8 \pm 4.1$ & $25.5 \pm 4.5$ \\
\hline Creatinine concentration [mg/dl] & $1.80 \pm 0.69$ & $1.76 \pm 0.74$ & $1.78 \pm 0.70$ \\
\hline Creatinine clearance [ml/min] & $58.4 \pm 24.4$ & $51.5 \pm 19.7$ & $55.5 \pm 22.7$ \\
\hline Alanine aminotransferase [U/l] & $31.5 \pm 21.5$ & $31.3 \pm 17.9$ & $31.4 \pm 20.0$ \\
\hline Aspartate aminotransferase [U/l] & $26.6 \pm 10.1$ & $26.1 \pm 10.4$ & $26.4 \pm 10.2$ \\
\hline Number of patients & & & \\
\hline Sex (male/female) & $34 / 27^{*}$ & $19 / 26^{*}$ & $53 / 53$ \\
\hline CsA/Tac & $28 / 24$ & $21 / 15$ & $49 / 39$ \\
\hline Corticosteroids treatment & $54(88.5 \%)$ & $42(93.3 \%)$ & $96(90.6 \%)$ \\
\hline Gastrointestinal disorders & $45(73.8 \%)$ & $22(48.9 \%)$ & $67(63.2 \%)$ \\
\hline Diabetes & $18(29.5 \%)$ & $13(28.9 \%)$ & $31(29.2 \%)$ \\
\hline
\end{tabular}

${ }^{*} p<0.05$ (MMF group vs. non-MMF group); BMI - body mass index, CSA - cyclosporine, MMF-mycophenolate mofetil, Tac - tacrolimus

lected. The hexane was evaporated to dryness under nitrogen at $40^{\circ} \mathrm{C}$. The residue was dissolved in $200 \mu \mathrm{l}$ of mobile phase (methanol with $0.025 \%$ of BHT for retinol and $\alpha$-tocopherol; hexane with dioxane in $97: 3$ volumetric ratio for $\beta$-carotene), transferred into vials and $20 \mu \mathrm{l}$ was injected into the HPLC system. For retinol and $\alpha$-tocopherol, the flow rate was $1.2 \mathrm{ml} / \mathrm{min}$ and the column was thermostatic at $20^{\circ} \mathrm{C}$ with simultaneous ultraviolet (325 nm for retinol) and fluorescence (excitation wavelength of $295 \mathrm{~nm}$ and emission wavelength of $325 \mathrm{~nm}$ for $\alpha$-tocopherol) detections. For $\beta$-carotene, the flow rate was $1.5 \mathrm{ml} / \mathrm{min}$ with photodiode-array ultraviolet detection $(450 \mathrm{~nm})$. The sample preparation was processed under a stream of nitrogen and in dim light.

The inter-day precision, expressed as mean coefficient of variation, was $7.4 \%$ for retinol (within concentration range $0.05-2.00 \mathrm{mg} / \mathrm{l}), 8.8 \%$ for $\alpha$-tocopherol (within concentration range $1.0-30.0 \mathrm{mg} / \mathrm{l}$ ) and $7.8 \%$ for $\beta$-carotene (within concentration range $0.1-2.0 \mathrm{mg} / \mathrm{l})$. The inter-day absolute accuracy was $3.5 \%, 5.7 \%$ and $4.1 \%$ for retinol, $\alpha$-tocopherol and $\beta$-carotene, respectively.

\section{Pharmacokinetic parameters of mycophenolate mofetil metabolites}

For pharmacokinetic analyses plasma MPA and MPAG concentrations were determined using the HPLC method described previously [22, 23]. The following pharmacokinetic parameters for MPA and MPAG were calculated: pre-dose concentration $\left(C_{0}\right)$, maximum concentration $\left(C_{\max }\right)$ and area under the plasma concentration - time curve from 0 to $4 \mathrm{~h}$ $\left(\mathrm{AUC}_{0-4} \mathrm{~h}\right)$ using the linear trapezoidal rule based on six time points determination (before the morning dose of MMF, 40 min, 1, 2, 3, and $4 \mathrm{~h}$ after dosing). Pharmacokinetic parameters were normalized to the MMF dose (per gram of MMF) (data not shown).

\section{Dietary intake}

Each patient was subjected to a diet history questionnaire to estimate $24-\mathrm{h}$ food intake on the day preceding the collection of blood samples. The antioxidant vitamin intakes were analyzed on the basis of the patients' dietary history using Microsoft Access 2000 databases, which are the extended version of 'Tables of food composition and nutritive value' [24]. The reference norms of $10 \mathrm{mg} /$ day, $1 \mathrm{mg} /$ day and $5 \mathrm{mg} /$ day for $\alpha$-tocopherol, retinol and $\beta$-carotene, respectively, were assumed [25].

\section{Statistical analysis}

All statistical tests were performed using Statistica software version 8.0 (StatSoft) and a $p$ value lower than 0.05 was considered significant. Normality was determined by the Shapiro-Wilk test. The differences between variables were estimated using the Mann-Whitney test and for normally distributed data Student's $t$ test was applied. The results are presented as mean \pm standard deviation (SD). The correlations of data were tested using Pearson or Spearman correlation analysis for normally and non-normally distributed data, respectively. Pearson's $\chi^{2}$ test was used for the evalua- 
tion of qualitative data. Multivariate regression analysis was applied to evaluate the interactions between several variables and their influence on the levels of plasma antioxidant vitamins.

\section{Results}

Plasma retinol concentrations ranged from $0.58 \mathrm{mg} / \mathrm{l}$ to $3.83 \mathrm{mg} / \mathrm{l}$ and were statistically lower in patients treated with MMF compared to the nonMMF group. Plasma retinol levels were also found to be significantly lower in patients suffering from gastrointestinal disorders. Retinol concentrations were statistically higher when $\mathrm{CL}_{\mathrm{cr}}$ was lower than $60 \mathrm{ml} / \mathrm{min}$ and when $C_{c r}$ was above $1.5 \mathrm{mg} / \mathrm{dl}$. The ALT above $36 \mathrm{U} / \mathrm{I}$ was associated with lower retinol levels (Table II). Retinol concentrations were negatively associated with AST and positively with MPAG $\mathrm{AUC}_{0-4 \mathrm{~h}}$ and MPAG $\mathrm{C}_{0}$ (Table III).

Plasma $\alpha$-tocopherol concentrations ranged from values below the lower limit of quantification (LLOQ) to $25.63 \mathrm{mg} / \mathrm{l}$. The concentrations of $\alpha$-tocopherol were significantly lower in patients treated with CNI (Table II). Moreover, a positive correlation was observed between $\alpha$-tocopherol levels and AST. Plasma $\alpha$-tocopherol concentrations correlated negatively with MPA $C_{0}$ (Table III).

$\beta$-Carotene concentrations ranged from values below the LLOQ to $3.22 \mathrm{mg} / \mathrm{l}$. Despite the lack of difference in dietary intake between men and women, $\beta$-carotene concentrations were higher in women and when MMF was co-administered with CsA compared to MMF co-administered with Tac. The concentrations of $\beta$-carotene were significantly lower in patients suffering from diabetes and from gastrointestinal disorders (Table II).

We also verified whether MMF treatment and pharmacokinetics of MMF metabolites (MPA and MPAG) correlate with patients' clinical condition. MMF treatment was associated with more frequent gastrointestinal disorders (Table I). Additionally, some MPA and MPAG pharmacokinetic parameters correlated with liver or kidney function. MPA $C_{0}$ was inversely dependent on ALT $(p=0.018)$, AST $(p=0.050)$ and $\mathrm{CL}_{c r}(p<0.001)$, while all MPAG

Table II. Concentrations of retinol, $\alpha$-tocopherol and $\beta$-carotene (mean \pm SD) in relation to MMF, CNI co-administered and patients' clinical condition

\begin{tabular}{|c|c|c|c|c|c|c|c|c|}
\hline Parameter & & $n$ & $\begin{array}{l}\text { Retinol } \\
{[\mathrm{mg} / \mathrm{l}]}\end{array}$ & Value of $p$ & $\begin{array}{c}\alpha \text {-Tocopherol } \\
{[\mathrm{mg} / \mathrm{l}]}\end{array}$ & Value of $p$ & $\begin{array}{c}\beta \text {-Carotene } \\
{[\mathrm{mg} / \mathrm{l}]}\end{array}$ & Value of $p$ \\
\hline All patients & & 106 & $1.56 \pm 0.76$ & & $9.47 \pm 5.42$ & & $0.34 \pm 0.37$ & \\
\hline \multirow[t]{2}{*}{ MMF } & Yes & 61 & $1.22 \pm 0.45$ & \multirow[t]{2}{*}{$<0.001$} & $9.39 \pm 4.85$ & \multirow[t]{2}{*}{0.812} & $0.32 \pm 0.43$ & \multirow[t]{2}{*}{0.200} \\
\hline & No & 45 & $2.03 \pm 0.86$ & & $9.59 \pm 6.19$ & & $0.35 \pm 0.26$ & \\
\hline \multirow[t]{2}{*}{ MMF with } & CsA & 28 & $1.12 \pm 0.39$ & \multirow[t]{2}{*}{0.220} & $9.77 \pm 4.99$ & \multirow[t]{2}{*}{0.484} & $0.45 \pm 0.62$ & \multirow[t]{2}{*}{0.046} \\
\hline & $\mathrm{Tac}$ & 24 & $1.28 \pm 0.51$ & & $9.16 \pm 5.17$ & & $0.25 \pm 0.19$ & \\
\hline \multirow[t]{2}{*}{$\mathrm{CNI}$} & Yes & 88 & $1.58 \pm 0.81$ & \multirow[t]{2}{*}{0.807} & $8.90 \pm 5.23$ & \multirow[t]{2}{*}{0.026} & $0.36 \pm 0.39$ & \multirow[t]{2}{*}{0.153} \\
\hline & No & 18 & $1.47 \pm 0.46$ & & $12.25 \pm 5.62$ & & $0.24 \pm 0.16$ & \\
\hline \multirow{2}{*}{$\begin{array}{l}\text { Gastrointestinal } \\
\text { disorders }\end{array}$} & Yes & 67 & $1.25 \pm 0.48$ & \multirow[t]{2}{*}{0.049} & $9.35 \pm 5.32$ & \multirow[t]{2}{*}{0.533} & $0.26 \pm 0.18$ & \multirow[t]{2}{*}{0.031} \\
\hline & No & 39 & $1.55 \pm 0.70$ & & $10.34 \pm 5.56$ & & $0.46 \pm 0.56$ & \\
\hline \multirow[t]{2}{*}{$\mathrm{CL}_{\mathrm{cr}}[\mathrm{ml} / \mathrm{min}]$} & $<60$ & 71 & $1.68 \pm 0.83$ & \multirow[t]{2}{*}{0.021} & $8.93 \pm 5.56$ & \multirow[t]{2}{*}{0.108} & $0.36 \pm 0.43$ & \multirow[t]{2}{*}{0.853} \\
\hline & $\geq 60$ & 35 & $1.32 \pm 0.54$ & & $10.58 \pm 5.04$ & & $0.29 \pm 0.20$ & \\
\hline \multirow[t]{2}{*}{$\mathrm{C}_{\mathrm{cr}}[\mathrm{mg} / \mathrm{dl}]$} & $>1.5$ & 56 & $1.70 \pm 0.82$ & \multirow[t]{2}{*}{0.027} & $9.04 \pm 6.00$ & \multirow[t]{2}{*}{0.327} & $0.37 \pm 0.45$ & \multirow[t]{2}{*}{0.296} \\
\hline & $\leq 1.5$ & 50 & $1.40 \pm 0.66$ & & $9.96 \pm 4.71$ & & $0.30 \pm 0.25$ & \\
\hline \multirow[t]{2}{*}{ ALT [U/I] } & $>36$ & 28 & $1.35 \pm 0.74$ & \multirow[t]{2}{*}{0.019} & $10.03 \pm 4.40$ & \multirow[t]{2}{*}{0.322} & $0.28 \pm 0.22$ & \multirow[t]{2}{*}{0.311} \\
\hline & $\leq 36$ & 78 & $1.64 \pm 0.76$ & & $9.10 \pm 5.67$ & & $0.32 \pm 0.24$ & \\
\hline \multirow[t]{2}{*}{ AST [U/I] } & $>36$ & 13 & $1.36 \pm 0.51$ & \multirow[t]{2}{*}{0.491} & $11.05 \pm 3.28$ & \multirow[t]{2}{*}{0.190} & $0.23 \pm 0.16$ & \multirow[t]{2}{*}{0.170} \\
\hline & $\leq 36$ & 93 & $1.59 \pm 0.79$ & & $9.16 \pm 5.58$ & & $0.32 \pm 0.24$ & \\
\hline \multirow[t]{2}{*}{ Sex } & Male & 53 & $1.53 \pm 0.77$ & \multirow[t]{2}{*}{0.750} & $9.42 \pm 5.30$ & 0.813 & $0.28 \pm 0.23$ & 0.041 \\
\hline & Female & 53 & $1.59 \pm 0.76$ & & $9.53 \pm 5.59$ & & $0.39 \pm 0.46$ & \\
\hline Diabetes & Yes & 31 & $1.64 \pm 0.83$ & 0.418 & $9.17 \pm 5.59$ & 0.929 & $0.25 \pm 0.23$ & 0.001 \\
\hline & No & 75 & $1.54 \pm 0.75$ & & $9.25 \pm 5.34$ & & $0.34 \pm 0.24$ & \\
\hline
\end{tabular}

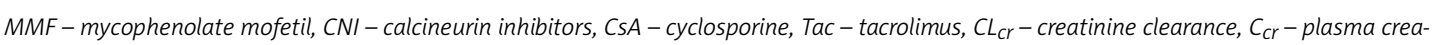
tinine, ALT - alanine aminotransferase, AST - aspartate aminotransferase 
Table III. Univariate regression analysis for retinol, $\alpha$-tocopherol and $\beta$-carotene in relation to MMF metabolites pharmacokinetic parameters and patients' clinical condition

\begin{tabular}{|c|c|c|c|c|c|c|c|}
\hline \multirow[t]{2}{*}{ Parameter } & \multirow[t]{2}{*}{$n$} & \multicolumn{2}{|c|}{$\begin{array}{l}\text { Retinol } \\
{[\mathrm{mg} / \mathrm{l}]}\end{array}$} & \multicolumn{2}{|c|}{$\begin{array}{c}\alpha \text {-Tocopherol } \\
{[\mathrm{mg} / \mathrm{l}]}\end{array}$} & \multicolumn{2}{|c|}{$\begin{array}{c}\beta \text {-Carotene } \\
{[\mathrm{mg} / \mathrm{l}]}\end{array}$} \\
\hline & & $r$ & $p$ & $r$ & $p$ & $r$ & $p$ \\
\hline ALT $[U / l]$ & 106 & -0.145 & 0.140 & 0.051 & 0.603 & -0.155 & 0.114 \\
\hline AST [U/I] & 106 & -0.248 & 0.011 & 0.265 & 0.006 & -0.137 & 0.165 \\
\hline MPA AUC $_{0-4 h}[\mathrm{mg} \times \mathrm{h} / \mathrm{l}]$ & 61 & 0.082 & 0.534 & -0.152 & 0.247 & 0.151 & 0.249 \\
\hline $\mathrm{MPA} \mathrm{C}_{0}[\mathrm{mg} / \mathrm{l}]$ & 61 & 0.211 & 0.105 & -0.286 & 0.027 & 0.021 & 0.875 \\
\hline MPAG AUC $\mathrm{C}_{0-4 \mathrm{~h}}[\mathrm{mg} \times \mathrm{h} / \mathrm{l}]$ & 61 & 0.312 & 0.026 & 0.025 & 0.861 & 0.158 & 0.267 \\
\hline MPAG $C_{0}[\mathrm{mg} / \mathrm{l}]$ & 61 & 0.295 & 0.035 & 0.071 & 0.621 & 0.071 & 0.618 \\
\hline
\end{tabular}

ALT - alanine aminotransferase, AST - aspartate aminotransferase, MPA - mycophenolic acid, AUC $0-4 \mathrm{~h}$ - area under the plasma concentration - time curve from 0 to $4 \mathrm{~h}, \mathrm{CO}_{\mathrm{O}}$ - predose concentration, MPAG - 7-O-mycophenolic acid glucuronide

pharmacokinetic parameters $\left(\mathrm{AUC}_{0-4 \mathrm{~h}}, \mathrm{C}_{0}\right.$ and $\left.\mathrm{C}_{\max }\right)$ were inversely dependent on $\mathrm{CL}_{\mathrm{Cr}}\left(\mathrm{CL}_{\mathrm{cr}}>60 \mathrm{ml} / \mathrm{min}\right.$ and $\mathrm{CL}_{\mathrm{cr}}<60 \mathrm{ml} / \mathrm{min}$ ) ( $p<0.001$ for each pharmacokinetic parameter).

The factors which significantly influenced the concentrations of vitamins as well as MMF metabolites in univariate analysis were analyzed in multivariate regression. It was found that the influences of some factors, e.g. diabetes and gastrointestinal disorders on $\beta$-carotene concentration, $\mathrm{CL}_{\mathrm{cr}}$ on retinol concentration, and kind of $\mathrm{CNI}$ applied on $\alpha$-tocopherol, were statistically insignificant in multivariate regression. However, in the same way as in the univariate analysis, the significant influence of AST and MMF treatment on retinol concentration $(p<0.001)$ as well as the $\beta$-carotene concentration dependence on sex $(p=0.037)$ were also observed in the multivariate regression models. In the multivariate regression analysis $\beta$-carotene was not dependent on type of CNI co-administered.

The current dietary intakes of studied vitamins in the daily food ration showed lower than recommended intakes in all studied patients. Moreover, similar intakes of analyzed vitamins were observed in patients treated and not treated with MMF as well as within the MMF group in relation to $\mathrm{CNI}$ applied (Table IV).

\section{Discussion}

The determination of plasma vitamins constitutes part of a study concerning the influence of MMF on the nutritional status of renal transplant recipients. Although the concentrations of retinol, $\beta$-carotene and $\alpha$-tocopherol detected in our study are comparable to those previously described, the latter concerned different populations or groups of patients $[18,19,21,26,27]$. Our results showed that the $\beta$-carotene concentration was dependent on sex. This corroborates the findings of other authors [28-30]. Although some studies indicated a relationship between retinol [29] as well as $\alpha$-tocopherol [30] and gender, we found no such correlation.

In our study only retinol concentrations were lower in patients treated with MMF. We did not observe any differences in $\alpha$-tocopherol and $\beta$-carotene concentrations between the MMF and non-MMF group. However, $\beta$-carotene was dependent on the administered CNI since $\beta$-carotene concentrations were significantly lower in patients treated with MMF and with Tac compared to those

Table IV. Dietary intake of antioxidant vitamins in patients treated in relation to MMF and MMF co-administered with CNI

\begin{tabular}{|c|c|c|c|c|c|c|}
\hline \multirow[t]{2}{*}{ Vitamin } & & \multicolumn{2}{|c|}{$M^{\prime} F^{*}$} & \multicolumn{2}{|c|}{ MMF in combination with* } & \multirow{2}{*}{$\begin{array}{c}\text { All patients } \\
(n=106)\end{array}$} \\
\hline & & Yes $(n=61)$ & No $(n=45)$ & $\operatorname{CsA}(n=28)$ & $\operatorname{Tac}(n=24)$ & \\
\hline \multirow[t]{2}{*}{ Retinol } & {$[\mathrm{mg}]$} & $0.79 \pm 0.62$ & $0.80 \pm 0.60$ & $0.88 \pm 0.79$ & $0.68 \pm 0.30$ & $0.79 \pm 0.61$ \\
\hline & $\%$ RDA & $87.2 \pm 66.4$ & $88.3 \pm 60.5$ & $95.9 \pm 81.1$ & $76.2 \pm 35.5$ & $87.7 \pm 63.7$ \\
\hline \multirow[t]{2}{*}{$\alpha$-Tocopherol } & [mg] & $7.10 \pm 4.41$ & $7.63 \pm 5.28$ & $7.47 \pm 5.53$ & $6.59 \pm 3.48$ & $7.32 \pm 4.77$ \\
\hline & $\%$ RDA & $73.7 \pm 44.2$ & $80.3 \pm 54.1$ & $77.0 \pm 55.6$ & $69.3 \pm 35.2$ & $76.4 \pm 48.5$ \\
\hline \multirow[t]{2}{*}{$\beta$-Carotene } & {$[\mathrm{mg}]$} & $0.20 \pm 0.46$ & $0.13 \pm 0.17$ & $0.22 \pm 0.60$ & $0.13 \pm 0.18$ & $0.17 \pm 0.37$ \\
\hline & $\%$ RDA & $40.6 \pm 92.8$ & $26.0 \pm 34.5$ & $44.3 \pm 120.7$ & $26.5 \pm 36.5$ & $34.5 \pm 74.2$ \\
\hline
\end{tabular}

MMF-mycophenolate mofetil, CSA - cyclosporine, Tac-tacrolimus, RDA - recommended daily allowance; *differences statistically insignificant 
who received the MMF and CSA regimen. To our knowledge, ours is the first such study in adult patients; however, in children [31] there were no differences observed in $\beta$-carotene concentrations in relation to $\mathrm{CNI}$ applied, probably due to the small number of patients in particular groups (14 and 9 patients for CSA and Tac, respectively).

Additionally, we observed lower retinol as well as $\beta$-carotene concentrations in patients suffering from gastrointestinal disorders. More frequent gastrointestinal disorders in patients treated with MMF appeared to have led to a decrease in retinol absorption.

Our results indicate that plasma retinol may be associated with kidney function. High retinol concentrations were related to increased $\mathrm{C}_{\mathrm{cr}}$ and decreased $\mathrm{CL}_{\mathrm{cr}}$. Furthermore, we observed positive correlations between retinol concentration and MPAG pharmacokinetic parameters, which may have resulted from the MPAG and retinol concentration dependence on renal function. These correlations are consistent with those of other authors [26, 32, 33]. In fact, Botella-Carretero et al. [26] described a positive correlation between the retinol concentration and $\mathrm{C}_{\mathrm{cr}}(r=0.464 ; p<0.001)$ in 80 obese patients (BMI $\geq 40 \mathrm{~kg} / \mathrm{m}^{2}$ ) suffering from non-alcoholic fatty liver disease. Gavrilov et al. [32] showed in multiple myeloma patients, and Abahusain et al. [33] in diabetics, a higher serum retinol concentration associated with chronic renal insufficiency. It may suggest a decreased retinol elimination in these patients.

In addition, our results indicate that plasma retinol may also be related to liver function, as low retinol concentrations were associated with higher ALT and AST activity. Botella-Carretero et al. [26] found a negative correlation between retinol and AST activity $(r=-0.236 ; p=0.036)$ and also between retinol and ALT activity $(r=-0.241$; $p=0.032$ ). Consequently, the authors suggested a protective retinol effect on the liver.

Unlike other authors, we observed a positive correlation between $\alpha$-tocopherol and AST, whereas we did not find any correlation with ALT. The relationship between ALT and $\alpha$-tocopherol has been presented in several studies [34-36], while a similar relationship with AST has been described only in one article [34]; however, the research was conducted in rats. In some studies, the favorable impact of vitamin E supplementation on either $\operatorname{ALT}[34,35]$ or AST decreases [34] was indicated. In addition, low $\alpha$-tocopherol concentration was stated to be a reliable marker of hepatocyte damage, independently of the increase in aminotransferase activity [36].

The negative correlation between $\alpha$-tocopherol and MPA $C_{0}$ may be caused by the dependence of $\alpha$-tocopherol and MPA $C_{0}$ on AST. The present study seems to be the first to report an influence of MMF on $\alpha$-tocopherol.
In the present study, the significantly lower $\beta$-carotene concentrations in diabetic patients corroborates published data [37-39]. It makes our results more relevant, as the protective role of $\beta$-carotene in diabetes prophylaxis has been suggested by many authors [37-41].

In conclusion, we found that MMF treatment significantly influences retinol concentrations. MMF treatment as well as the incidence of gastrointestinal disorders were associated with lower plasma retinol concentrations, which may be caused by decreased retinol absorption. Diet adjustment and/or including vitamin A supplementation should be considered in such patients.

\section{Acknowledgments}

This study was supported by Grant No. 501-0203306413-02324-50382 from Poznan University of Medical Sciences. Mycophenolic acid phenyl glucuronide (MPAG) for analytical purposes was kindly supplied by Roche Pharmaceuticals (Palo Alto, USA).

\section{References}

1. Teplan V, Valkovsky I, Teplan V, Stollova M, Vyhnanek F, Andel M. Nutritional consequences of renal transplantation. J Renal Nutr 2009; 19: 95-100.

2. Arns W. Noninfectious gastrointestinal (GI) complications of mycophenolic acid therapy: a consequence of local GI toxicity? Transplant Proc 2007; 39: 88-93.

3. Kasiske BL, Vazquez MA, Harmon WE, et al. Recommendations for the outpatient surveillance of renal transplant recipients. American Society of Transplantation. J Am Soc Nephrol 2000; 11 (Suppl 15): S1-86.

4. Davies NM, Grinyó J, Heading R, Maes B, Meier-Kriesche HU, Oellerich M. Gastrointestinal side effects of mycophenolic acid in renal transplant patients: a reappraisal. Nephrol Dial Transplant 2007; 22: 2440-8.

5. Duda G, Saran A. Polish recommendations concerning vitamins and minerals consumed by elderly people [Polish]. Farm Współcz 2008; 1: 16-23.

6. Toigo G, Aparicio M, Attman PO, et al. Expert working group report on nutrition in adult patients with renal insufficiency (Part 2 of 2). Clin Nutr 2000; 19: 281-91.

7. Morris RG. Immunosuppressant drug monitoring: is the laboratory meeting clinical expectations? Ann Pharmacother 2005; 39: 119-27.

8. Ostalska-Nowicka D, Malinska A, Silska M, Perek B, Zachwieja J, Nowicki M. Mycophenolate mofetil (MMF) treatment efficacy in children with primary and secondary glomerulonephritis. Arch Med Sci 2011; 7: 1042-8.

9. Machnicki G, Lentine KL, Salvalaggio PR, Burroughs TE, Brennan DC, Schnitzler MA. Kidney transplant Medicare payments and length of stay: associations with comorbidities and organ quality. Arch Med Sci 2011; 7: 278-86.

10. Mamelok R. From mechanisms to long-term benefits. Transplantation 2005; 79 (3 Suppl): S43-4.

11. Staatz CE, Tett SE. Clinical pharmacokinetics and pharmacodynamics of mycophenolate in solid organ transplant recipients. Clin Pharmacokinet 2007; 46: 13-58.

12. Grygiel-Górniak B, Przysławski J. Oxidative stress and select mineral components intake among obese women 
using hormonal replacement therapy [Polish]. Żyw Człow Metab 2007; 34: 199-203.

13. Armeni T, Principato G, Quiles JL, Pieri C, Bompadre S, Battino M. Mitochondrial dysfunctions during aging: vitamin E deficiency or caloric restriction - two different ways of modulating stress. J Bioenerg Biomembr 2003; 35: 181-91.

14. Chau N, Tebi A, Creton C, Belbraouet S, Debry G. Relationship between plasma retinol and infectious diseases in the elderly. A case-control study. Ann Nutr Metab 2000; 44: 256-62.

15. Ito Y, Wakai K, Suzuki K, et al. Lung cancer mortality and serum levels of carotenoids, retinol, tocopherols, and folic acid in men and women: a case-control study nested in the JACC Study. J Epidemiol 2005; 15: S140-9.

16. Wakai K, Suzuki K, Ito Y, et al. Serum carotenoids, retinol, and tocopherols, and colorectal cancer risk in a Japanese cohort: effect modification by sex for carotenoids. Nutr Cancer 2005; 51: 13-24

17. Ozasa K, Ito Y, Suzuki K, et al. Serum carotenoids and other antioxidative substances associated with urothelial cancer risk in a nested case-control study in Japanese men. J Urol 2005; 173: 1502-6.

18. Wierzbicka A, Pawłowska J, Socha P, et al. Lipid, carbohydrate metabolism, and antioxidant status in children after liver transplantation. Transplant Proc 2007; 39: 1523-5.

19. Siluk D, Oliveira RV, Esther-Rodriguez-Rosas M, et al. $A$ validated liquid chromatography method for the simultaneous determination of vitamins $A$ and $E$ in human plasma. J Pharm Biomed Anal 2007; 44: 1001-7.

20. High KP, Legault C, Sinclair JA, Cruz J, Hill K, Hurd DD. Low plasma concentrations of retinol and alpha-tocopherol in hematopoietic stem cell transplant recipients: the effect of mucositis and the risk of infection. Am J Clin Nutr 2002; 76: 1358-66.

21. Rajendran V, Pu YS, Chen BH. An improved HPLC method for determination of carotenoids in human serum. J Chromatogr B 2005; 824: 99-106.

22. Seebacher G, Weigel G, Wolner E, et al. A simple HPLC method for monitoring mycophenolic acid and its metabolite in transplant recipients. Clin Chem Lab Med 1999; 37: 409-15.

23. Graj J, Chrzanowska M. Validation of HPLC method for therapeutic drug monitoring of mycophenolic acid in renal transplant recipients. Probl Ter Monit 2006; 1: 3-10.

24. Kunachowicz H, Nadolna I, Przygoda B, Iwanow K (eds). Tables of food composition and nutritive value [Polish]. PZWL, Warsaw 2005

25. Ziemlański Ś, Bułhak-Jachymczyk B, Budzyńska-Topolowska J, et al. Normy żywienia dla ludności w Polsce [Polish]. Nowa Med 1998; 4: 1-27.

26. Botella-Carretero JI, Balsa JA, Vázquez C, Peromingo R, Díaz-Enriquez M, Escobar-Morreale HF. Retinol and alphatocopherol in morbid obesity and nonalcoholic fatty liver disease. Obes Surg 2010; 20: 69-76.

27. Palli D, Decarli A, Russo A, et al. Plasma levels of antioxidant vitamins and cholesterol in a large population sample in central-northern Italy. Eur J Nutr 1999; 38: 90-8.

28. Curran-Celentano J, Hammond BR, Ciulla TA, Cooper DA, Pratt LM, Danis RB. Relation between dietary intake, serum concentrations, and retinal concentrations of lutein and zeaxanthin in adults in a Midwest population. Am J Clin Nutr 2001; 74: 796-802.

29. Faure H, Preziosi P, Roussel AM, et al. Factors influencing blood concentration of retinol, alpha-tocopherol, vitamin $\mathrm{C}$, and beta-carotene in the French participants of the SU.VI.MAX trial. Eur J Clin Nutr 2006; 60: 706-17.
30. Xiang J, Nagaya T, Huang XE, et al. Sex and seasonal variations of plasma retinol, alpha-tocopherol, and carotenoid concentrations in Japanese dietitians. Asian Pac J Cancer Prev 2008; 9: 413-6.

31. Granot E, Elinav H, Kohen R. Markers of oxidative stress in cyclosporine-treated and tacrolimus-treated children after liver transplantation. Liver Transpl 2002; 8: 469-75.

32. Gavrilov V, Yermiahu T, Gorodischer R. Renal pathology and retinol status in multiple myeloma patients. Kidney Int 2006; 69: 173-7.

33. Abahusain MA, Al-Nahedh NN. The biochemical status of vitamin A and alpha-tocopherol during different stages of renal disease and its relationship to diabetes. Saudi J Kidney Dis Transpl 2002; 13: 18-23.

34. Zaidi SM, Al-Qirim TM, Banu N. Effects of antioxidant vitamins on glutathione depletion and lipid peroxidation induced by restraint stress in the rat liver. Drugs R D 2005; 6: 157-65.

35. Okita M, Hayashi M, Sasagawa T, et al. Effect of a moderately energy-restricted diet on obese patients with fatty liver. Nutrition 2001; 17: 542-7.

36. Fan XP, Wang K, Liu Y, Wang JF. Plasma alpha-tocopherol is negatively correlated with hepatocyte apoptosis in chronic hepatitis B patients. Intern Med 2009; 48: 1585-93.

37. Abahusain MA, Wright J, Dickerson JW, de Vol EB. Retinol, alpha-tocopherol and carotenoids in diabetes. Eur J Clin Nutr 1999; 53: 630-5.

38. Coyne T, Ibiebele TI, Baade PD, et al. Diabetes mellitus and serum carotenoids: findings of a population-based study in Queensland, Australia. Am J Clin Nutr 2005; 82: 685-93.

39. Giammarioli S, Filesi C, Vitale B, Cantagallo A, Dragoni F, Sanzini E. Effect of high intakes of fruit and vegetables on redox status in type 2 onset diabetes: a pilot study. Int J Vitam Nutr Res 2004; 74: 313-20.

40. Sugiura M, Nakamura M, Ogawa K, et al. Associations of serum carotenoid concentrations with the metabolic syndrome: interaction with smoking. Br J Nutr 2008; 100: 1297-306.

41. Ylönen K, Alfthan G, Groop L, Saloranta C, Aro A, Virtanen SM. Dietary intakes and plasma concentrations of carotenoids and tocopherols in relation to glucose metabolism in subjects at high risk of type 2 diabetes: the Botnia Dietary Study. Am J Clin Nutr 2003; 77: 1434-41. 